\title{
Analysis on the Cultural Connotation of Gansu Province Tourist Slogan and its Systematic Translation in Multi-contexts
}

\author{
Yanlin Wang \\ Tourism College, Northwest Normal University, Lanzhou, Gansu Province, China \\ mykyky@163.com
}

Keywords: Gansu tourist slogan, Jiaoxiang Silu Ruyi Gansu, cultural connotation, multiple context, translation

\begin{abstract}
This paper analyzes the cultural connation of the tourist slogan of Gansu Province, China, and tentatively provides different translations considering different contexts. The slogan has been applied in the tourism advertising both officially by relevant governmental departments and commercially by travel agencies, while its English translation was quite far from satisfaction. The existing translation version used is "Amazing Gansu along the Silk Road" and "Symphony Silk Road, Desirable Gansu". The translation fails to transmit enough cultural connation of the source text which leads to a big information leakage. Meanwhile the translation is not orally catchy in terms of rhythm and rhyme. To explore a better translation, the paper specifically analyzes the cultural connotation of each word in the slogan, and search for the most proper diction for its English equivalence. On the basis of careful and professional search, the paper provides the systematic translation of the slogan with the consideration of its multi-contexts in application.
\end{abstract}

\section{The Introduction: no satisfying translation for “交响丝路, 如意甘肃”}

On September 27, 2018, the 3rd Silk Road (Dunhuang) International Culture Expo and Tourism Forum was held in Dunhuang, Gansu Province, China. The author received a translation work about the conference documents commissioned by the Gansu Provincial Department of Culture and Tourism. During the translation, it was found that the widely used tourist slogan of Gansu Province “交响丝路, 如意甘肃” has no accepted English translation. Therefore, the author conducts a translation exploration based on the translation work and attempts to construct the English translation system in multi-contexts.

\section{The cultural connotation of “交响丝路, 如意甘肃” and the diction for its translation}

\subsection{The text interpretation and cultural connotation of the word “丝路”}

More than 2,000 years ago, the industrious and brave people on the Eurasian continent explored a number of trade and humanities communication channels connecting Asia, Europe and Africa. Later generations collectively referred to them as the "Silk Road". [1] In 2013, President Xi Jinping proposed a major initiative to jointly build the "Silk Road Economic Belt" and the "21st Century Maritime Silk Road”. Now the "One Belt, One Road" construction has transformed from a vision to an action, "The development strategy, focusing on economic cooperation such as infrastructure construction, injecting new impetus into the world economy, quickly ignited the enthusiasm and imagination of the relevant countries and regions. The symphony of the new Silk Road has become a strong voice at the new historical starting point." [2].

Therefore, the associative meaning of the term “丝路” comprises both the ancient Silk Road in history and the great initiative of the "One Belt, One Road" in contemporary China. Therefore the English equivalence of the word can be selectively adapted to "the Silk Road" or the "Belt and Road". 


\subsection{The text interpretation and cultural connotation of the word “交响”}

The origin of symphonic music enjoys a long history. Its name can be derived from ancient Greece, meaning "voice together”. It comprises meanings of both “ harmony” and “chord”. In ancient Rome, it evolved into a generic term for all instrumental ensembles and recitals. [3]

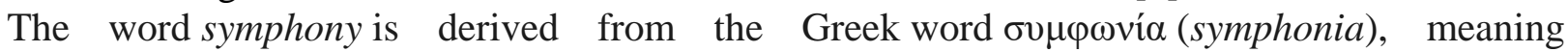
"agreement or concord of sound", "concert of vocal or instrumental music", from $\sigma 0 ́ \mu \varphi \omega v o \varsigma$ (symphōnos), "harmonious". [4]

The Silk Road symphony under the "Belt and Road Initiative" is the music of the Silk Road spirit and the economic development and cultural integration. The Silk Road spirit of "unity, mutual trust, equality and mutual benefit, tolerance and mutual benefit, cooperation and mutual benefit" is the most beautiful part of the symphony.

Based on its musical significance, the word “交响” is the semantic integration of the historical origins, cultural communication, and economic cooperation.

Therefore, in the Chinese-English translation, the semantic elements of "symphony, symphonic, harmony" must be retained in the English translation since these words have indispensable cultural connotations in the source language.

\subsection{The text interpretation and cultural connotation of the word “如意”}

The famous Taoist scholar Zhu Quan of the Ming Dynasty recorded that Ruyi was firstly created by the Yellow Emperor, used as the weapon in the war with Chiyou. Because Ruyi is the weapon of the earliest age, it has its original function of driving evil spirits. The form of Ruyi changed later and its handle ends appear as the shape of the finger, so it can reach where the hand can't reach to scrach the itching part, so it is called " as your wish" , commonly known as "not asking for people". Later the meaning of Ruyi was integrated with the culture of jade. "The gentleman is like jade" and the appearance of jade Ruyi combines the virtues of jade with the auspicious meaning, which achieved the widest popularity in China. [5]

The traditional Chinese auspicious culture represented by "Yu Ruyi” reflects people's good wishes for a better life. It is also a reflection of people's pursuit of happiness and harmony. The text “如意甘肃” skillfully combines the shape of Gansu Province on map with "Jade Ruyi” and the beautiful connotation of "Yu Ruyi", which not only conveys the topographical information of Gansu province, but also conveys the beautif ul auspicious will. Therefore, when considering the translation, the meaning of Ruyi must be contained. The English equvilalent words of Ruyi can be determined as “ harmony, harmonious, fecility, or auspicious". If possible, the Chinese pinyin "Ruyi" should be kept in the translation to pass the typical cultural symbols in Chinese culture by using the foreignization translation strategy to preserve cultural elements of the source language. Through the understanding of the word "Ruyi", the readers can appreciate the typical cultural symbols of the heterogeneous cultures and fully interpret the cultural background of Ruyi. This can also achieve the cultural communication function carried by the translation to a greater extent.

At the same time, the tourism propaganda slogan is an information-based style, and the text capacity is limited. Therefore, the word “甘肃” should be used as it is in Pinyin with an irreplaceable semantic meaning, which must be clearly highlighted in the translation. 


\subsection{The interpretation of the source text “交响丝路, 如意甘肃” and the diction for its translation}

Table 1: Interpretation and Diction of the source text

\begin{tabular}{cccc}
\hline Source text & \multicolumn{2}{l}{ Semantic and cultural interpretation } & \\
\hline 交响 & Symphony, harmony & Symphonious, harmonious & Symphonic, harmonic \\
\hline 丝路 & The Silk Road & The Belt and Road & \\
\hline 如意 & Ruyi, harmony & Ruyi Jade, harmonious & Fecility, auspicious \\
\hline 甘肃 & Gansu & & \\
\hline
\end{tabular}

\section{The translation system of “交响丝路, 如意甘肃” in multi-contexts}

The tourism slogan which is of an information-based style is usually short and succinct with a large amount of information, and the literary, artistic, propaganda and advertising purpose. Therefore, in terms of the overall translation, its rhythm, rhyme and emotional function must be considered as a whole, so that the translation can be orally catchy and arouse the reader's beautiful association.

Through the above interpretation of the text, the following information points could be drawn: Symphony - Silk Road - Symphony Silk Road, Jade Ruyi - Ruyi Gansu - harmonious and beautiful. Therefore, according to the different contexts used in the translation, these information points and their corresponding words can be processed into different parts of speech and combined into different language structures.

\subsection{The translation used independently as a tourist slogan}

When used independently as a tourist slogan, the author translated “交响丝路, 如意甘肃” as : "Symphonious the Silk Road, Harmonious Gansu of Ruyi Jade”, using symphonious and harmonious to form the rhythm, visual rhyme and "meaning" rhyme, using the alienation strategy, Ruyi and the jade culture are embedded in the translation, this way the target audience could experience the heterogeneity of Chinese culture. Additionally the word "jade" and "road" form a rhyme. This translation can be used in stand-alone text contexts such as websites, billboards, promotional videos, and more.

\subsection{Translations used in documents}

When used in documents, the context and grammar rules can be considered to determine how the translation is used. For example, at the 3rd ICIF Tourism Forum, Gansu Provincial Governor Tang Renjian's speech mentioned: "I hope that everyone... really appreciates the charm of Jiaoxiang Silu, Ruyi Gansu". The translation is a noun phrase, so the word "charm" in the source language can be matched as follows: to experience the charm of "Symphonious Silk Road, and Harmonious Gansu of Ruyi Jade". When "Ruyi Gansu" is used independently in the document, the translation "Harmonious Gansu of Ruyi Jade" can be used. The translation "Symphonious Silk Road" can be changed also to "the Silk Road Symphony” or "the Symphony of the Silk Road”.

\subsection{The translation when emphasizing the background of the "Belt and Road" initiative}

If the emphasis on the background element of "Belt and Road", the following translation "Symphonious the Belt and Road, Harmonious Gansu of Ruyi Jade" should be used. In this translation, replacing the Silk Road with the Belt and Road highlights the "One Belt, One Road" initiative proposed by China, suggesting the status and important historical and cultural significance of Gansu in the context of the "Belt and Road". Harmonious and symphonious not only evoke the rhyme, but also naturally reflect the inseparable relationship between the Silk Road and Gansu. 


\subsection{Translations used with other tourist slogans}

On November, 2018, the Gansu Provincial Department of Culture and Tourism held a tourism promotion in Shanghai with a slogan “通哌丝路美食, 遇见如意甘肃”. When translating the slogan, the author combined its translation with "Symphonious the Silk Road, Harmonious Gansu of Ruyi Jade".

The translation is as follows: "Enjoying Gourmet Food on the Belt and Road, Encountering Harmonious Gansu of Ruyi Jade” . "Enjoying” and "Encountering” form the perfect alliteration and tail rhyme, and the length of the syllable is quite similar so it is orally catchy. The word "gourmet" forms the rhyme with "Gansu" below, while the word "harmonious" interprets the meaning of the word "Ruyi". "Ruyi Jade" uses the foreignized translation strategy to load the Chinese cultural elements. The word "jade" forms the ending rhyme with the words "food, road" of the first sentence.

\subsection{The systematic translation in multiple contexts}

Table 1: The systematic translation in multiple contexts

\begin{tabular}{|c|c|c|}
\hline Contexts & Translation & Application settings \\
\hline Independent application & $\begin{array}{l}\text { Symphonious the Silk Road } \\
\text { Harmonious Gansu of Ruyi Jade }\end{array}$ & $\begin{array}{l}\text { Title of documents, websites, or } \\
\text { billborads }\end{array}$ \\
\hline Divided application & $\begin{array}{l}\text { The Symphony of Silk Road } \\
\text { Harmonious Gansu }\end{array}$ & $\begin{array}{l}\text { Official speech, } \\
\text { documents }\end{array}$ \\
\hline Functional application & $\begin{array}{l}\text { Symphonious the Belt and Road, } \\
\text { Harmonious Gansu of Ruyi Jade }\end{array}$ & $\begin{array}{c}\text { Documents } \\
\text { Official promotion with emphasis } \\
\text { on B\&R }\end{array}$ \\
\hline Integrated application & $\begin{array}{l}\text { “邂䞧丝路美食, 遇见如意甘肃” } \\
\text { “Enjoying Gourmet Food on the Belt } \\
\text { and Road, } \\
\text { Encountering Harmonious Gansu of } \\
\text { Ruyi Jade” }\end{array}$ & $\begin{array}{l}\text { Official documents } \\
\text { Promotions } \\
\text { Title of billboards }\end{array}$ \\
\hline
\end{tabular}

\section{Summary}

This paper analyzes the cultural connotation of Gansu tourism propaganda slogan, fully considers the function of tourism slogan, and provides different options for the use of the slogan in multiple contexts. However, there is no end to translation, and there is no fixed rule in translation. Hopefully this article can be used to generate a better translation.

\section{References}

[1] Vision and proposed actions outlined on jointly building Silk Road Economic Belt and 21st-Century Maritime Silk Road issued by the State Council of the PRC, 2015.3 pp.1-2.

[2] Southern Weekend. May 11, 2017.

[3] https://baike.baidu.com/item/\%E4\%BA\%A4\%E5\%93\%8D\%E4\%B9\%90/720471?fr=aladdin

[4] https://en.wikipedia.org/wiki/Symphony

[5] https://baike.baidu.com/item/\%E5\%A6\%82\%E6\%84\%8F/254746?fr=aladdin 